\title{
DUCTILITY DEMAND FOR UNI-DIRECTIONAL AND REVERSING PLASTIC HINGES IN DUCTILE MOMENT RESISTING FRAMES
}

\author{
Richard Fenwick $^{1,3}$, Raad Dely ${ }^{2}$ and Barry Davidson ${ }^{1}$
}

\begin{abstract}
In a major earthquake the beams in moment resisting frames may develop either reversing or unidirectional plastic hinges. The form of plastic hinge depends upon the ratio of the moments induced by the gravity loading to those induced by the seismic actions. Where this ratio is low the plastic hinges form at the ends of the beams and the sign of the inelastic rotation changes with the direction of sway. These are reversing plastic hinges, and the magnitude of the rotation that they sustained is closely related to the inter-storey displacement. However, when the moment ratio exceeds a certain critical value, unidirectional plastic hinges may form. In this case negative moment plastic hinges develop at the column faces and the positive moment plastic hinges form in the beam spans. As the earthquake progresses the positive and negative inelastic rotations accumulate in their respective zones so that peak values are always sustained at the end of the earthquake. With this type of plastic hinge no simple relationship exists between inter-storey drift and inelastic rotation.

Several series of time history analyses have been made to assess the relative magnitudes of inelastic rotation that are imposed on the two forms of plastic hinge. It is found that with design level earthquakes typically the unidirectional plastic hinge is required to sustain $2 \frac{1 / 2}{2}$ to 4 times the rotation imposed on reversing plastic hinges, with the curvature ductilities ranging up to 140 . These values are appreciably in excess of the values measured in tests using standard details. This indicates that in structures where unidirectional plastic hinges may form, the design displacement ductility and or the allowable inter-storey drift should be reduced below the maximum values currently permitted in the New Zealand codes. The problems associated with the formation of unidirectional plastic hinges can be avoided by adding positive moment flexural reinforcement in the mid regions of the beams. By this means the potential positive moment plastic hinges can be restricted to the beam ends.
\end{abstract}

\subsection{INTRODUCTION}

With current design practice, moment resisting multi-storey frame structures are generally designed to perform in a ductile manner in a major earthquake. The required level of ductility is achieved by ensuring that a ductile beam sway mechanism forms in preference to a column sway mechanism. This results in the majority of plastic hinges forming in the beams and it is the behaviour of these that very largely determines the dynamic performance of the structure.

Two different forms of plastic hinge may develop in the beams of a frame subjected to seismic actions. These are illustrated in Fig. 1. When the seismic induced shear is greater than the shear resulting from the gravity loading, reversing plastic hinges develop as illustrated in Fig. 1a, with the maximum positive and negative bending moments in the beams occurring at the column faces. With a reversal in the direction of sway the sign of the bending moments changes, and hence the direction of inelastic rotation sustained by each plastic hinge reverses. It is this action which gives rise to the term "reversing plastic hinge". Between the two plastic hinges in the beam the member remains elastic and essentially straight. With this form of plastic hinge the inelastic rotation that is sustained is closely associated with the inter-storey displacement and as such it can both increase and decrease as the earthquake progresses.

If the gravity loading is sufficiently high so that the associated shear is greater than the shear induced by the seismic bending moments, then a point of zero shear, together with its associated maximum bending moment, exists in the span. In this situation a negative plastic hinge would normally form against one column face and a positive moment plastic hinge forms in the span of the beam as illustrated in Fig. 1b. With a reversal in the direction of sway, a new negative moment plastic hinge forms against the column face at the other end of the beam and a new positive moment plastic hinge forms in the span. Additional

1 Civil and Resource Engineering, University of Auckland, (Member)

2 Post graduate student, Civil and Resource Engineering, University of Auckland

3 Fellow 

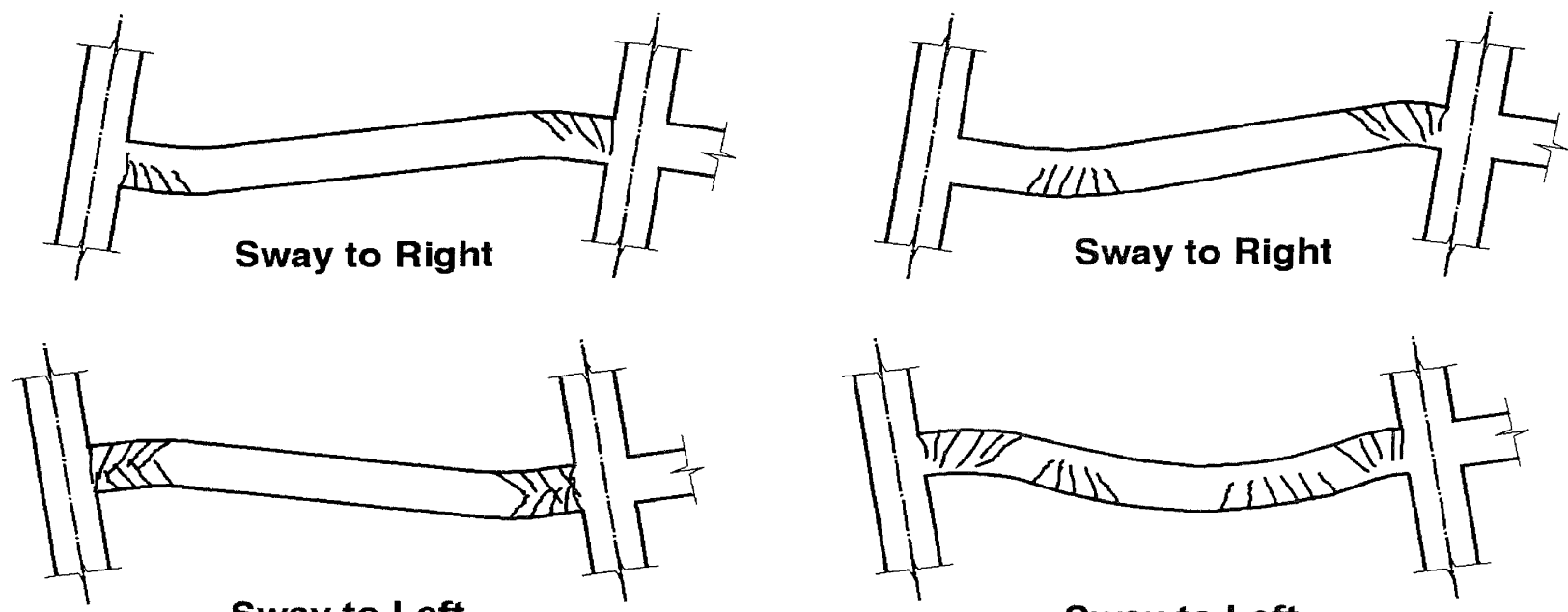

Sway to Left

Sway to Left

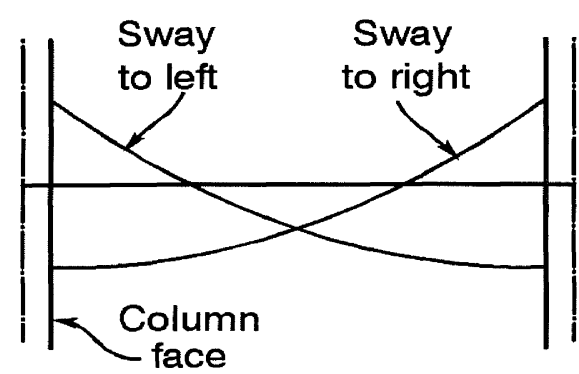

Bending Moments

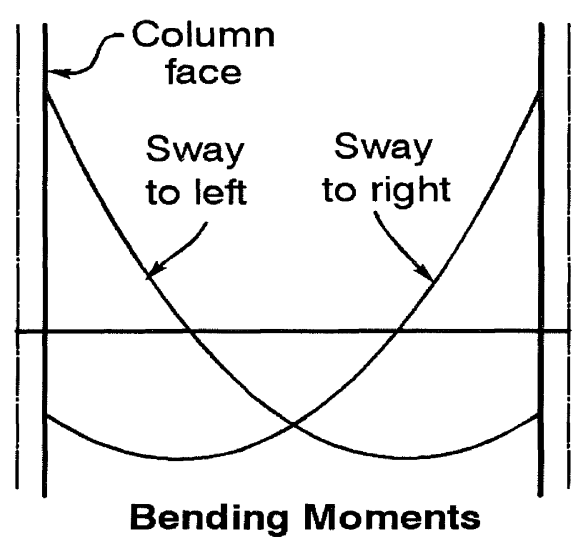

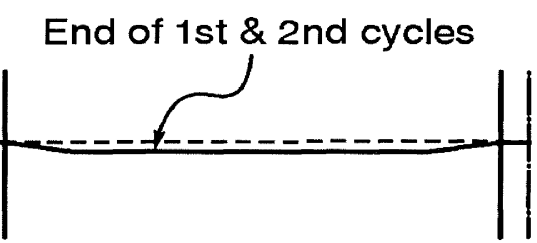

Deflected Shape

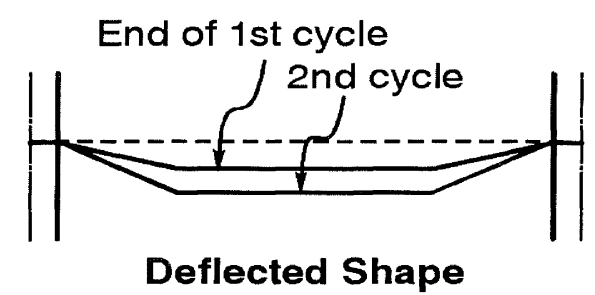

(b) Uni-directional plastic hinges

Figure 1: Reversing and unidirectional plastic hinges in beams.

inelastic displacements cause the rotations sustained by these plastic hinges to increase. This results in the beam developing the deflected shape shown in Fig. 1b. As the earthquake ground motion continues so the plastic hinge rotations and beam deflections accumulate. No decrease in these values is possible. With an increase in the duration of the earthquake, and /or an increase in the design structural ductility factor, a greater number of inelastic excursions occurs and hence the magnitude of the plastic hinge rotations increase. This is in contrast to the beams which form reversing plastic hinges, where the deformation depends on the maximum inter-storey deflection that is sustained, and the duration of the strong ground motion has no direct effect. The way in which unidirectional plastic hinges develop in beams has been described in a previous analytical studies $[1,2]$ and it has been observed in a laboratory test [3].

The formation of unidirectional plastic hinges may be prevented by increasing the positive moment flexural strength of a beam, as illustrated in Fig. 2. Additional positive moment reinforcement is added and it is 
anchored by standard hooks at a distance of close to one beam depth from each column face. With this arrangement the critical section of the beam for potential positive moment plastic hinges can located in the same zone as for the potential negative moment plastic hinges, thus giving potential reversing plastic hinge zones.

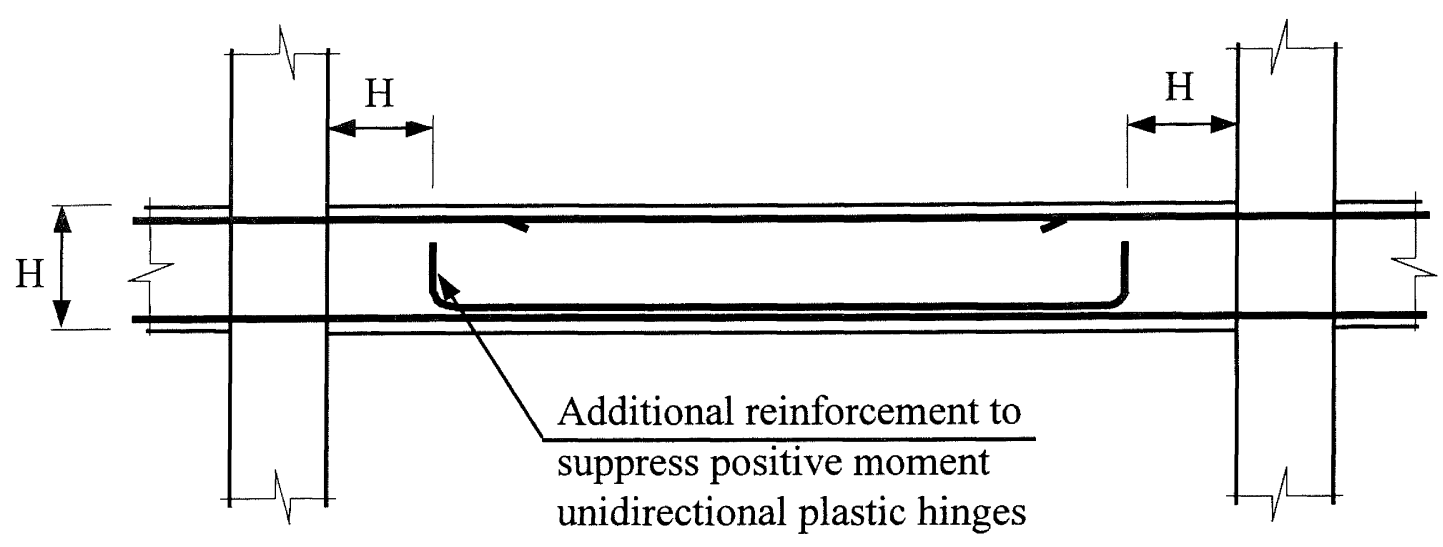

Figure 2: Additional reinforcement to restrict formation of unidirectional plastic hinges.

For a prismatic beam the critical level of uniformly distributed vertical force, $\mathrm{w}_{\mathrm{o}}$, which separates beams which form unidirectional plastic hinges from those that form reversing plastic hinges, can be related to the beam flexural strengths by the expression

$$
\mathbf{w}_{0}=2\left(M_{1}+M_{2}\right) / L^{2}
$$

where $M_{1}$ and $M_{2}$ are the positive and negative flexural strengths of the beam at alternative ends and $\mathrm{L}$ is the clear span. For the purposes of this paper the value of $w_{0}$ has been calculated from the design flexural strengths. It should be noted that in practice the vertical force on the beam arises from gravity loads together with additional forces arising from the vertical excitation of the beam. However, in the analyses reported in this paper actions arising from vertical accelerations have been neglected.

The negative and positive unidirectional plastic hinges which form in a beam have different characteristics. Negative moment plastic hinges develop in zones of high shear and this confines their lengths. High strains are induced in the reinforcement and relatively high strain hardening results. To assess the appropriate strain hardening rates for this situation the test results of a number of beams, which were reinforced with 300 grade reinforcement, were examined. It was found that for both reversing and negative moment unidirectional plastic hinges the strain hardened bending moment, $\mathrm{M}_{\text {max }}$, could be assessed from

$$
\mathbf{M}_{\max }=\mathbf{M}_{y}(1+5 \theta)
$$

where $M_{y}$ is the first yield strength of the beam and $\theta$ is the rotation in radians sustained in the plastic hinge zone. This expression has been used in this work to model the strain hardening characteristics on both negative moment unidirectional plastic hinges and reversing plastic hinges.
The positive moment plastic hinges form at locations of low shear, and as a result they spread over a relatively long length of beam. Analyses of typical cases indicates that the maximum reinforcement strains are of the order of one third to one fifth of the corresponding values sustained by negative moment plastic hinges carrying the same plastic hinge rotation. Consequently with positive moment, unidirectional plastic hinges there is appreciably less strain hardening than there is with the negative moment or reversing plastic hinges. In addition vertical ground accelerations continuously change the magnitude of the vertical forces acting on the beam; a factor which in practice contributes to the changing location of the maximum positive moment in the span. To allow for this effect the constant " 5 " in equation 2 has been replaced by a value of " 1 " for modelling the strain hardening characteristics of positive moment unidirectional plastic hinges.

The performance of reversing plastic hinges, such as may develop in frame structures in a severe earthquake, has been extensively researched and numerous tests have been carried out [4]. In addition many time history analyses have been made to assess the likely inelastic demands placed on these. As a result of this work design standards have been developed for codes of practice which enable reversing plastic hinge zones to be detailed with a high degree of confidence. However, this favourable situation does not exist for unidirectional plastic hinges, which may be expected to form in many medium rise moment resisting frame buildings. Very few tests have been carried out to assess the deformation capacity of this form of plastic hinge and only a few time history analyses have been made to determine the inelastic demands imposed on these.

In this paper the rotational demands imposed on these two forms of plastic hinge by design level earthquakes have been assessed in several series of time history analyses as listed below. This is a first step in assessing if current design 
standards are adequate for structures in which unidirectional plastic hinges may form.

1. In the first set of time history analyses the performance of a six storey frame and a portal frame were compared. The object was to see if the simpler portal frame model could be used to predict the displacement ductility and inelastic rotation demands, which developed in the more complete frame model.

2. In the second series the possible discrepancy involved in using a model which confined the inelastic deformation at four distinct points in each beam as against a more complex model where the plastic deformation was allowed to spread along the beam was examined.

3. In the third series the effect of using an $S_{p}$ factor of 1.0 instead of 0.67 was assessed.

4. In the fourth series the relative inelastic rotations were found for a range of design inter-storey deflections and ductility levels.

Additional details of the analyses and the results are given in reference 5 .

There are three factors which could be expected to be important in terms of the magnitude of the rotation imposed on unidirectional plastic hinge zones for earthquake records with the same response spectrum. These are briefly described below.

1. With an increase in the design structural ductility factor there is a decrease in strength and hence a greater number of inelastic excursions should occur for any given earthquake record. This in turn should lead to an increase in the accumulated inelastic rotation for unidirectional plastic hinges.

2. An increase in the duration of the strong ground motion should also increase the number of inelastic excursions, again leading to an increase in the imposed rotations.

3. Increasing the ratio of the maximum gravity load shear to the seismic shear results in the distance between the critical sections for the positive and negative plastic hinges being reduced. For a given inelastic displacement this increases the magnitude of the associated inelastic rotations, and hence it could be expected to increase the final accumulated rotations [6].

\subsection{ANALYTICAL MODELS AND GROUND MOTIONS}

\subsection{Ground Motions and Analyses}

Three artificial earthquake records were used in the analyses. They were developed by modifying the amplitude and frequency components of recorded earthquakes and recombining these so that the new artificial "earthquakes" gave a close fit to the elastic response spectrum with $5 \%$ damping, given in the New Zealand Loading Standard [7] for normal soils. The three seed earthquakes were:
1. El-Centro $1940 \mathrm{NS}$

2. Matahina ( at base of dam ), 1987 N83E, Edgecumbe earthquake

3. Hachinohe 1968, Tokachi-Oki NS

The resulting spectra are shown in Fig. 3 together with the target spectrum from the New Zealand Loadings Standard. The time acceleration histories for the three artificial ground motions are shown in Fig. 4. It can be seen that they vary considerably in their characteristics, such as their frequency content and duration of high intensity shaking.

The time history analyses were made using the dynamic analysis program DRAIN 2DX. The mass and stiffness damping values were set to give an equivalent of $5 \%$ viscous damping for the first two modes of the frame and $5 \%$ for the portal frames. In all the analyses the beams and associated plastic hinge zones were modelled by a bi-linear response with the strain hardening stiffnesses being determined as described in the previous section. To simplify the analyses as far as possible P-delta effects were not included.

\subsection{Representation of Plastic Hinge Zones}

The behaviour of structures which form reversing plastic hinges is different from those that develop unidirectional plastic hinges. With reversing plastic hinges in beams, that is for the case where there is no axial compression force, inelastic cyclic displacements lead to appreciable stiffness degradation in the portion of the force displacement relationship (loading curve) in which the structural actions and displacements are increasing. This arises principally due to shear deformation in the plastic hinge zones $[2,8]$. However, relatively little stiffness degradation develops for the unloading portions of the force deflection response. The application of axial compression to a plastic hinge reverses these trends. In this situation the stiffness degradation associated with the loading curves is reduced but with the unloading portions of the curve the stiffness degradation increases. Where unidirectional plastic hinges form in the beams little stiffness degradation occurs with either the loading or unloading. A consequence of this is that the bilinear hysteretic model gives a good representation of the behaviour.

Comparative analyses with single degree of freedom oscillators have shown that provided the hysteretic model is one that dissipates significant energy in each major inelastic cycle, the form of hysteretic response has only a minor influence on the maximum inelastic rotation $[9,10]$. On this basis a bi-linear model was used to assess the rotation demands with the reversing plastic hinges.

In most of the analyses reported in the paper the plastic hinge rotations were confined to specific locations in the beam. In practice, as mentioned previously, the yielding zone moves as strain hardening develops. To allow for this effect, the plastic hinge locations were first calculated on the basis of the nominal member strengths. Their positions were then reassessed allowing for strain hardening by assuming that all the unidirectional plastic hinge rotations increased to $2 \frac{1}{2}$ times the corresponding value for reversing plastic hinges. 
The reversing plastic hinge rotations were assessed from the design inter-storey deflection. The $2 \frac{1}{2}$ factor was found from a previous limited study [1]. For the analyses the selected plastic hinge location was chosen as mid way between the positions calculated with and without strain hardening.

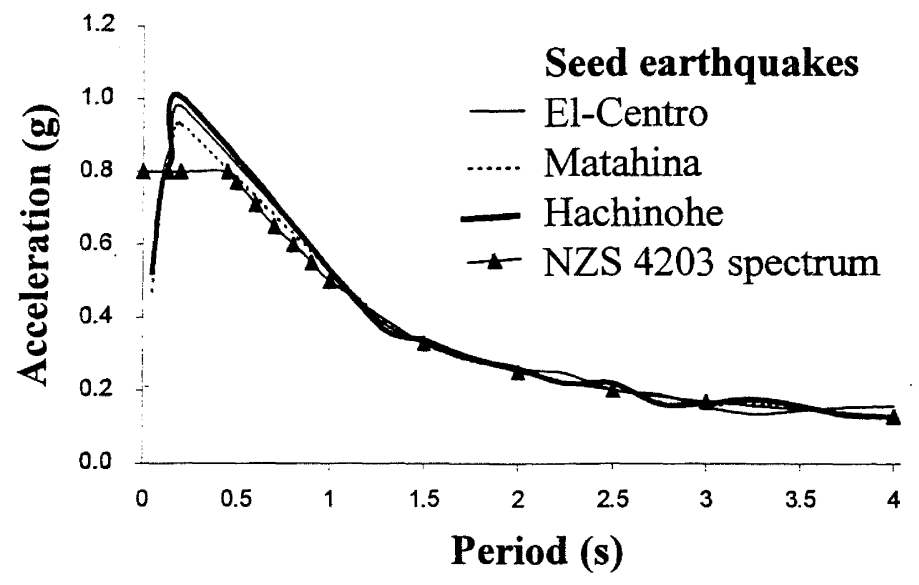

Figure 3: Response spectra for artificial earthquakes.

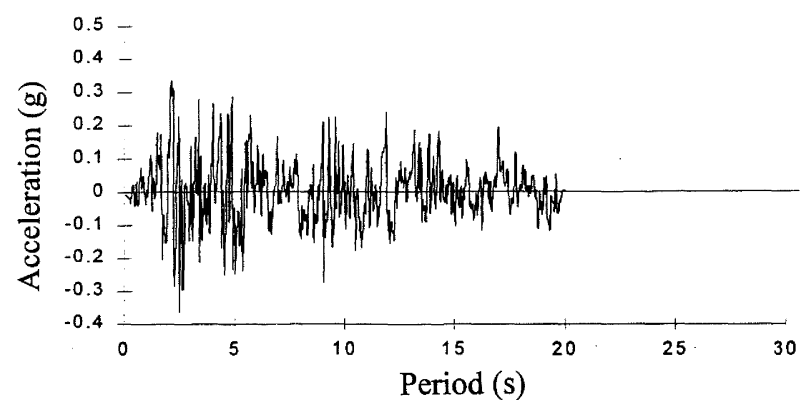

(a) Seed earthquake El-Centro

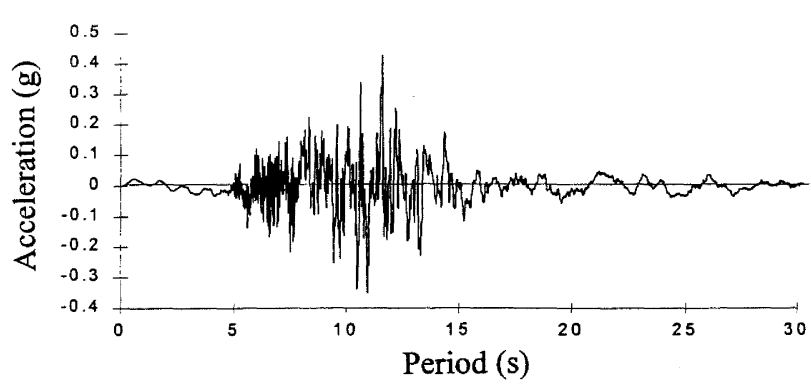

(b) Seed earthquake Matahina

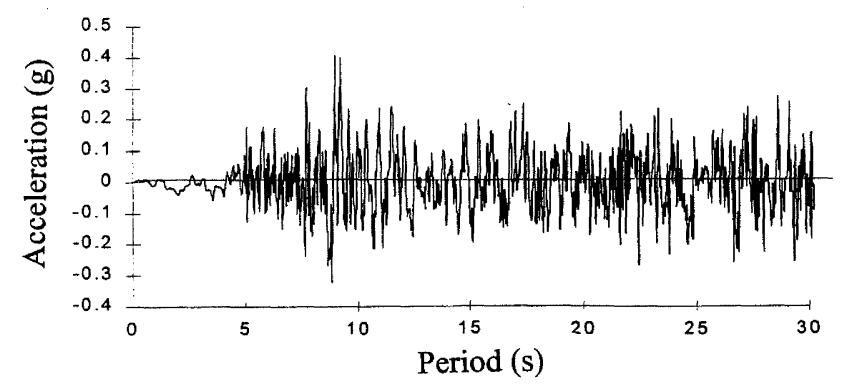

(c) Seed earthquake Hachinohe

Figure 4: Time acceleration histories for ground motions of artificial earthquakes. 


\subsection{Design Strengths and Stiffnesses}

The design strengths and member stiffnesses were found so that both the strength and interstorey deflection criteria given in the Loadings Standard [7] were satisfied. The analyses were based on the spectrum for intermediate soils. For the six storey frame and its associated portal frame in the first series of analyses a zone factor of 1.0 was used. In all the other cases a value of 1.2 was used. In all the analyses except for the third series a $S_{p}$ factor of 0.67 was assumed together with the corresponding member yield strengths being taken as the design strengths. With all the analyses the ground accelerations were multiplied by both the $S_{p}$ and zone factors. In the third series of analyses the $S_{p}$ factor was taken as unity and the design strengths were increased to the expected mean member strengths.

\subsection{SIX STOREY FRAME AND ASSOCIATED PORTAL FRAME}

\subsection{Six storey frame}

A 6 storey 3 bay frame was designed to resist both gravity loading on the beams and lateral seismic forces. A simplified floor plan for the building is shown in Fig. 5. In this structure the frames on lines $1,3,5$ and 7 are assumed to provide the seismic resistance in the y-direction while the structural walls resist the torsional actions and the seismic forces in the $\mathrm{x}$-direction. The frames on lines 2, 4 and 6 have been assumed to be flexible as far as lateral forces are concerned. The analysis is based on the frame on line 3 .

The member sizes were proportioned so that the maximum design inter-storey deflection for the ultimate limit state was close to the limit of 0.018 times the inter-storey height. The beam strengths were determined from the seismic and gravity load combinations specified in the Loadings Standard [7]. The gravity load combinations were critical for the upper three levels. In the lower three levels the moments were redistributed to equalise the critical values at each level. For the critical level the uniformly distributed vertical loading on the beam corresponded to a value of $2.9 \mathrm{w}_{\mathrm{o}}$ as given by Eq. 1. The column strengths were determined following the criteria given in Appendix A in the Concrete Standard [11]. To enable a comparison to be made with a frame which forms reversing plastic hinges the design strengths were reassessed for the case where the vertical loading on the beam was removed. However, the seismic mass at each level was not changed. Both frames were analysed for the three artificial ground motions. The fundamental period of both frames was 1.73 seconds.

\subsection{Portal Frame}

To obtain some idea of the variation that occurs with different structures and earthquake records a large number of results are required. These would be difficult to obtain if full frames were to be sized and analysed. To overcome this problem a two pin portal frame with rigid columns was designed with its characteristics set as close as possible to those of the full frame. The beam of the portal was dimensioned so that at the design ultimate limit state the inter-storey deflection was identical to that in the critical level of the 6 storey frame. In addition the fundamental periods of both the portal and six storey frame were identical, and the gravity loading on the beams of both the portal and six storey frame were identical in terms of the $w_{0}$ value defined in Equation 1. The lateral strength and strain hardening characteristics were made as close as possible to those of the 6 storey frame but an exact match was not possible. As with the frames, the analyses were repeated with the vertical loading removed from the beam so that the reversing plastic hinge case was obtained. Analyses were made with the three ground motions for the portal frame both with and without loading on the beam.

\subsection{Results of Time History Analyses}

The principal results of the time history analyses for the 6 storey and portal frames are given in Table 1. It can be seen that ductility levels and maximum plastic hinge rotations are in reasonable agreement between the portal and the critical actions in the six storey frame. The comparison is better for the structures, which form unidirectional plastic hinges than for those that form reversing plastic hinges. From these results it was concluded that the simpler portal frame models could be used to assess the magnitudes of the required plastic hinges rotations.

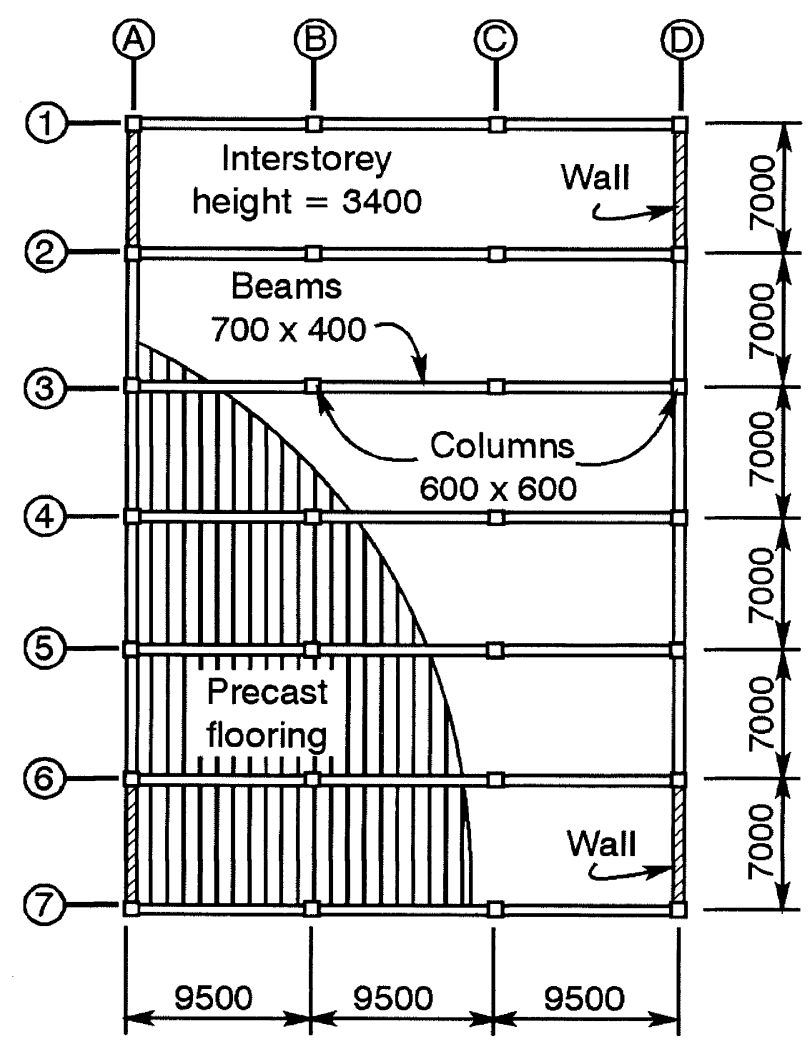

Figure 5: Plan on idealised building. 
Table 1: Results of time history analysis of the multi-storey and portal frames

\begin{tabular}{|c|l|c|c|c|}
\hline $\begin{array}{c}\text { Seed } \\
\text { Earthquake record }\end{array}$ & \multicolumn{1}{|c|}{$\begin{array}{c}\text { Frame } \\
\text { Description }\end{array}$} & $\begin{array}{c}\text { Loading on } \\
\text { beam }\end{array}$ & $\begin{array}{c}\text { Maximum } \\
\text { rotation } \\
\text { (radians) }\end{array}$ & $\begin{array}{c}\text { Displacement } \\
\text { ductility }\end{array}$ \\
\hline El-Centro & 6 storey frame & $2.9 \mathrm{w}_{\mathrm{o}}$ & 0.0437 & 5.1 \\
& Portal frame & $2.9 \mathrm{w}_{\mathrm{o}}$ & 0.0478 & 5.7 \\
& 6 storey frame & none & 0.0101 & 4.1 \\
& Portal frame & none & 0.0134 & 4.3 \\
\hline Matahina & 6 storey frame & $2.9 \mathrm{w}_{\mathrm{o}}$ & 0.0374 & 3.7 \\
& Portal frame & $2.9 \mathrm{w}_{\mathrm{o}}$ & 0.0322 & 4.2 \\
& 6 storey frame & none & 0.0107 & 4.2 \\
& Portal frame & none & 0.0206 & 6.0 \\
\hline Hachinohe & 6 storey frame & $2.9 \mathrm{w}_{\mathrm{o}}$ & 0.0627 & 5.8 \\
& Portal frame & $2.9 \mathrm{w}_{\mathrm{o}}$ & 0.0699 & 5.1 \\
& 6 storey frame & none & 0.0164 & 6.2 \\
& Portal frame & none & 0.0200 & 5.9 \\
\hline
\end{tabular}

\subsection{SPREAD AND CONCENTRATED PLASTIC HINGES}

With the DRAIN 2DX dynamic analysis program the plastic hinging is confined to a point on a beam. In the frame and portal models previously described four plastic hinge locations are identified in each beam, as described in section 2.0. With this representation the movement of the positive moment plastic hinges and the spread of the negative moment plastic hinge zones is not modelled. In this series of analyses the significance of this approximation was assessed by comparing the results from two sets of portal frames.

In the first set, each portal frame had four potential plastic hinge locations, while in the second set potential plastic hinges were spaced at close centres along the beam. With this latter representation strain hardening causes the inelastic rotations to spread from one plastic hinge location to the next. This effectively allows the movement of the centre of rotation to be modelled.
In both sets of models two pin rigid column portals were used. In each of these the section properties and flexural strength of the beam, together with the seismic mass and height of the columns, were selected to give 12 frames, which under the design ultimate condition would sustain a limiting deflection of 0.025 times the height. These parameters were chosen so that the frames in each set had fundamental periods of $1 / 3$ second to 4 seconds in steps of $1 / 3$ of a second. In addition four different levels of vertical loading were applied to each portal frame beam. The analyses were made for the artificial earthquake record based on the El-Centro record.

The principal results of the analyses are shown in Table 2 . No significant trends of the values with period were found and consequently the results from each set of 12 portal frames has been given as an average value. The results indicate that there is no significant difference between the values obtained from the two models.

Table 2: Averaged results for beams with spread and concentrated plastic hinges

\begin{tabular}{|l|c|c|c|}
\hline Plastic hinges & $\begin{array}{c}\text { Loading } \\
\text { on beam }\end{array}$ & $\begin{array}{c}\text { Max. rotation } \\
\text { (radians) }\end{array}$ & $\begin{array}{c}\text { Displacement } \\
\text { ductility }\end{array}$ \\
\hline localised & $0 \mathrm{w}_{\mathrm{o}}$ & 0.0265 & 7.1 \\
& $0 \mathrm{w}_{\mathrm{o}}$ & 0.0265 & 7.1 \\
\hline spread & $2 \mathrm{w}_{\mathrm{o}}$ & 0.0683 & 6.7 \\
localised & $2 \mathrm{w}_{\mathrm{o}}$ & 0.0670 & 6.5 \\
\hline spread & $3 \mathrm{w}_{\mathrm{o}}$ & 0.0687 & 6.5 \\
localised & $3 \mathrm{w}_{\mathrm{o}}$ & 0.0703 & 6.1 \\
\hline spread & $4 \mathrm{w}_{\mathrm{o}}$ & 0.0710 & 6.0 \\
localised & $4 \mathrm{w}_{\mathrm{o}}$ & 0.0705 & 5.7 \\
\hline
\end{tabular}


Consequently for the large number of analyses in the next series the simpler portal model was used. In these and subsequent analyses it was found that the level of beam loading, provided it exceeded the critical value for the formation of unidirectional plastic hinges, had a consistent but small influence of the magnitude of the inelastic rotation. Consequently the values obtained for the $2 w_{0}, 3 w_{0}$ and $4 w_{0}$ load levels have been averaged in the tables. The influence of the load level is examined in more detail in section 5.4

\subsection{INFLUENCE OF DIFFERENT FACTORS ON PLASTIC HINGE ROTATION}

\subsection{Structural Performance Factor}

The Loadings and Concrete Standards $[7,11]$ indicate that the structural performance factor should be taken as 0.67 . A number of reasons supporting this value are advanced in the Loadings Standard [7]. In general terms they can be summarised as-

(a). material strengths are generally higher than assumed in design,

(b). structural ductility levels are determined in tests by applying several cycles to displacements of + and - the design ductility value, while in an earthquake the actual structure only reaches the maximum displacement once without sustaining the extreme displacement cycles, (c). the methods of analysis are generally conservative in that the contribution of non-structural elements (such as cladding) to force resistance and damping is neglected, as is radiation damping associated with soil structure interaction.

Point (b) is not relevant to structures which form unidirectional plastic hinges as the inelastic deformation does not reverse and the maximum value is always sustained at the end of the record. Point (a) may be addressed by using the mean material strengths to determine the member strength rather than the design strength $\left(\phi M_{n}\right)$.

To assess the possible significance of using different $S_{p}$ factors two sets of analyses have been made. Each set consisted of the 12 portal frames with the analyses being repeated with gravity load levels of $2 \mathrm{w}_{0}, 3 \mathrm{w}_{0}, 4 \mathrm{w}_{0}$ and no loading on the beams. The analyses were made with the ElCentro based earthquake record with a design inter-storey drift of 0.025 times the inter-storey height. In the first set the member strengths were taken as the design strengths $\left(\phi \mathrm{M}_{\mathrm{n}}\right)$ and the ground motion accelerations were multiplied by the $S_{p}$ value of 0.67 . These analyses were then repeated with the design strengths increased by a factor of $1.08 / 0.85$ and the ground motion accelerations not reduced. The 1.08 value allows for the increase in strength of the reinforcement between the design strength and the average yield strength and the 0.85 factor corresponds to the strength reduction factor. A summary of the principal results of the analyses is given in Table 3 .

Table 3: Influence of $S_{p}$ factor on plastic hinge rotations and ductility.

\begin{tabular}{|c|c|c|c|c|c|c|}
\hline \multirow{2}{*}{$\begin{array}{c}\mathrm{S}_{\mathrm{p}} \\
\text { factor }\end{array}$} & \multicolumn{3}{|c|}{ Plastic Hinge Rotation (radians) } & \multicolumn{3}{|c|}{ Displacement Ductility } \\
\hline & $\begin{array}{c}\text { Uni- } \\
\text { directional }\end{array}$ & Reversing & Ratio & $\begin{array}{c}\text { Uni- } \\
\text { directional }\end{array}$ & Reversing & Ratio \\
\hline (a) 0.67 & $\begin{array}{c}0.069 \\
(0.012)^{*}\end{array}$ & $\begin{array}{c}0.0289 \\
(0.0104)\end{array}$ & 2.39 & $\begin{array}{c}6.40 \\
(0.95)\end{array}$ & $\begin{array}{c}7.24 \\
(0.74)\end{array}$ & 0.88 \\
\hline (b) 1.00 & $\begin{array}{c}0.0901 \\
(0.0152)\end{array}$ & $\begin{array}{c}0.0403 \\
(0.0037)\end{array}$ & 2.23 & $\begin{array}{c}8.83 \\
(1.32)\end{array}$ & $\begin{array}{l}10.93 \\
(0.83)\end{array}$ & 0.81 \\
\hline $\begin{array}{l}\text { Ratio } \\
\text { (b/a) }\end{array}$ & 1.31 & 1.39 & & 1.38 & 1.51 & \\
\hline
\end{tabular}

*Standard deviations given in brackets

The results indicate that with a $S_{p}$ factor of 1 the unidirectional plastic hinge rotations increase on average by $31 \%$ and the displacement ductilities by $39 \%$. These increases are considerable, and while the factors in point (c) above may still justify taking a $S_{p}$ factor of less than 1 it should clearly be greater than the current value of 0.67 for structures that form unidirectional plastic hinges. It is tentatively suggested that a value of 0.9 might be appropriate. This implies an average increase in the rotation of unidirectional plastic hinges of the order of 1.2 above that determined from analyses with a $S_{p}$ factor of 0.67 .

\subsection{Influence of Inter-storey Drift}

To investigate the influence of the magnitude of the design inter-storey drift a series of analyses were made with design inter-storey drifts of $0.025,0.020$ and 0.015 times the interstorey height. These analyses were made for the set of 12 portal frames and they were repeated with the four different beam loading levels (no load, $2 w_{0}, 3 w_{0}$, and $4 w_{0}$ ). Separate sets of analyses were made for the three different ground motions. In all cases the design strengths and deflections were determined using a structural ductility factor of 6 and a $\mathrm{S}_{\mathrm{p}}$ factor equal to 0.67 . The time history accelerations were 
also multiplied by the $S_{p}$ factor. Key results are summarised in Table 4.

From the table it can be seen that the ratio of the average rotations sustained by the unidirectional plastic hinge to those acting on the reversing plastic hinge ranged from 2.4 to 4.6. There is no apparent trend in these ratios with the magnitude of the inter-storey drift. However, it may be noted that the highest ratios are for the Hachinohe based earthquake record which has the longest duration of strong ground motion, see Fig. 4. It may also be noted that the displacement ductility is smaller for the portal frames that develop unidirectional plastic hinges. This is a consequence of the greater relative strain hardening that develops in these structures. This trend may also be seen in Table 5 for the higher ductility values.

Table 4: Influence of inter-storey deflection on plastic hinge rotation $(\mu=6.0)$

\begin{tabular}{|c|c|c|c|c|c|c|c|}
\hline \multirow[t]{2}{*}{ Earthquake } & \multirow[t]{2}{*}{ Drift } & \multicolumn{3}{|c|}{ Plastic Hinge Rotation (radians) } & \multicolumn{3}{|c|}{ Ductility } \\
\hline & & $\begin{array}{c}\text { Uni- } \\
\text { directional }\end{array}$ & Reversing & Ratio & $\begin{array}{c}\text { Uni- } \\
\text { directional } \\
\end{array}$ & Reversing & Ratio \\
\hline \multirow[t]{3}{*}{ El-Centro } & $0.025 \mathrm{H}$ & $\begin{array}{c}0.069 \\
(0.012)^{*}\end{array}$ & $\begin{array}{c}0.029 \\
(0.010)\end{array}$ & 2.40 & $\begin{array}{c}6.40 \\
(0.95)\end{array}$ & $\begin{array}{c}7.24 \\
(0.74)\end{array}$ & 0.88 \\
\hline & $0.02 \mathrm{H}$ & $\begin{array}{c}0.055 \\
(0.012)\end{array}$ & $\begin{array}{c}0.022 \\
(0.003)\end{array}$ & 2.52 & $\begin{array}{c}6.54 \\
(0.87)\end{array}$ & $\begin{array}{c}7.54 \\
(0.79)\end{array}$ & 0.87 \\
\hline & $0.015 \mathrm{H}$ & $\begin{array}{c}0.043 \\
(0.009)\end{array}$ & $\begin{array}{c}0.017 \\
(0.002)\end{array}$ & 2.60 & $\begin{array}{c}6.84 \\
(0.94)\end{array}$ & $\begin{array}{c}7.64 \\
(0.77)\end{array}$ & 0.90 \\
\hline \multirow[t]{3}{*}{ Matahina } & $0.025 \mathrm{H}$ & $\begin{array}{c}0.062 \\
(0.007)\end{array}$ & $\begin{array}{c}0.018 \\
(0.004)\end{array}$ & 3.47 & $\begin{array}{c}5.21 \\
(0.73)\end{array}$ & $\begin{array}{c}5.17 \\
(0.88)\end{array}$ & 1.01 \\
\hline & $0.02 \mathrm{H}$ & $\begin{array}{c}0.051 \\
(0.006)\end{array}$ & $\begin{array}{c}0.015 \\
(0.003)\end{array}$ & 3.43 & $\begin{array}{c}5.29 \\
(0.80)\end{array}$ & $\begin{array}{c}5.48 \\
(0.86)\end{array}$ & 0.97 \\
\hline & $0.015 \mathrm{H}$ & $\begin{array}{c}0.040 \\
(0.005) \\
\end{array}$ & $\begin{array}{c}0.011 \\
(0.002) \\
\end{array}$ & 3.57 & $\begin{array}{c}5.42 \\
(0.84) \\
\end{array}$ & $\begin{array}{c}5.52 \\
(0.86) \\
\end{array}$ & 0.98 \\
\hline \multirow[t]{3}{*}{ Hachinohe } & $0.025 \mathrm{H}$ & $\begin{array}{c}0.088 \\
(0.019)\end{array}$ & $\begin{array}{c}0.034 \\
(0.005)\end{array}$ & 2.58 & $\begin{array}{c}5.49 \\
(1.43)\end{array}$ & $\begin{array}{c}5.81 \\
(1.20)\end{array}$ & 0.95 \\
\hline & $0.02 \mathrm{H}$ & $\begin{array}{c}0.074 \\
(0.017)\end{array}$ & $\begin{array}{c}0.017 \\
(0.004)\end{array}$ & 4.46 & $\begin{array}{c}5.65 \\
(1.51)\end{array}$ & $\begin{array}{c}6.09 \\
(1.31)\end{array}$ & 0.93 \\
\hline & $0.015 \mathrm{H}$ & $\begin{array}{c}0.059 \\
(0.012)\end{array}$ & $\begin{array}{c}0.013 \\
(0.004)\end{array}$ & 4.57 & $\begin{array}{c}5.87 \\
(1.59)\end{array}$ & $\begin{array}{c}6.13 \\
(1.40)\end{array}$ & 0.96 \\
\hline
\end{tabular}

*Standard deviations given in brackets.

The values in Table 4 clearly indicate that the magnitude of the inelastic rotation sustained by the unidirectional plastic hinges increases with the design inter-storey drift. On average reducing the design inter-storey drift ratio from 0.025 to 0.020 and 0.015 reduced the rotations to 81 and 65 percent respectively.

\subsection{Influence of Ductility}

The sets of analyses described in Section 5.2 were repeated to investigate the effect of varying the ductility on the plastic hinge rotations. For these analyses the design inter-storey drift ratio was held constant at 0.025 with the analyses being repeated with design structural ductility factors of 2, 4 and 6 . Key results are summarised in Table 5 . It can be seen that the magnitude of the inelastic rotation increases with the ductility. On average the inelastic rotations sustained with the design ductilities of 4 and 2 are 66 and 28 percent of the corresponding ductility 6 values respectively. 
Table 5: Influence of ductility on plastic hinge rotation $(\mathrm{Drift}=0.025 \mathrm{H})$

\begin{tabular}{|c|c|c|c|c|c|c|c|}
\hline \multirow{2}{*}{$\begin{array}{l}\text { Structural } \\
\text { ductility } \\
\text { factor }\end{array}$} & \multirow[t]{2}{*}{ Earthquake } & \multicolumn{3}{|c|}{ Plastic Hinge Rotation (radians) } & \multicolumn{3}{|c|}{ Displacement Ductility } \\
\hline & & $\begin{array}{c}\text { Uni- } \\
\text { directional }\end{array}$ & Reversing & Ratio & $\begin{array}{c}\text { Uni- } \\
\text { directional }\end{array}$ & Reversing & Ratio \\
\hline 6 & El-Centro & $\begin{array}{c}0.069 \\
(0.012)\end{array}$ & $\begin{array}{c}0.029 \\
(0.010)\end{array}$ & 2.40 & $\begin{array}{c}6.40 \\
(0.95)\end{array}$ & $\begin{array}{c}7.24 \\
(0.74)\end{array}$ & 0.88 \\
\hline 4 & & $\begin{array}{c}0.044 \\
(0.010)\end{array}$ & $\begin{array}{c}0.017 \\
(0.002)\end{array}$ & 2.61 & $\begin{array}{c}3.53 \\
(0.49)\end{array}$ & $\begin{array}{c}3.37 \\
(0.62)\end{array}$ & 1.04 \\
\hline 2 & & $\begin{array}{c}0.018 \\
(0.007)\end{array}$ & $\begin{array}{c}0.012 \\
(0.008)\end{array}$ & 1.52 & $\begin{array}{c}1.80 \\
(0.27)\end{array}$ & $\begin{array}{c}1.73 \\
(0.33)\end{array}$ & 1.04 \\
\hline 6 & Matahina & $\begin{array}{c}0.062 \\
(0.007)\end{array}$ & $\begin{array}{c}0.018 \\
(0.004)\end{array}$ & 3.47 & $\begin{array}{c}5.21 \\
(0.73)\end{array}$ & $\begin{array}{c}5.17 \\
(0.88)\end{array}$ & 1.01 \\
\hline 4 & & $\begin{array}{c}0.043 \\
(0.006)\end{array}$ & $\begin{array}{c}0.014 \\
(0.004)\end{array}$ & 3.05 & $\begin{array}{c}3.33 \\
(0.43)\end{array}$ & $\begin{array}{c}3.26 \\
(0.59)\end{array}$ & 1.02 \\
\hline 2 & & $\begin{array}{c}0.019 \\
(0.004)\end{array}$ & $\begin{array}{c}0.010 \\
(0.003)\end{array}$ & 2.01 & $\begin{array}{c}1.75 \\
(0.20)\end{array}$ & $\begin{array}{c}1.70 \\
(0.21)\end{array}$ & 1.03 \\
\hline 6 & Hachinohe & $\begin{array}{c}0.088 \\
(0.019)\end{array}$ & $\begin{array}{c}0.034 \\
(0.005)\end{array}$ & 2.58 & $\begin{array}{c}5.49 \\
(1.43)\end{array}$ & $\begin{array}{c}5.81 \\
(1.20)\end{array}$ & 0.95 \\
\hline 4 & & $\begin{array}{c}0.057 \\
(0.016)\end{array}$ & $\begin{array}{c}0.014 \\
(0.005)\end{array}$ & 4.04 & $\begin{array}{c}3.28 \\
(0.93)\end{array}$ & $\begin{array}{c}3.30 \\
(0.80)\end{array}$ & 0.99 \\
\hline 2 & & $\begin{array}{c}0.023 \\
(0.005)\end{array}$ & $\begin{array}{c}0.008 \\
(0.003)\end{array}$ & 2.84 & $\begin{array}{c}1.72 \\
(0.18)\end{array}$ & $\begin{array}{c}1.72 \\
(0.017)\end{array}$ & 1.00 \\
\hline
\end{tabular}

\subsection{Influence of Beam Load Level}

The results of all the portal frame analyses covered in Tables 4 and 5 have been examined to assess the influence of the beam loading on the plastic hinge rotations. Increasing the load level results in a small but consistent increase in rotation. The average ratio of the inelastic unidirectional plastic hinge rotations sustained by the $3 w_{0}$ to $2 w_{0}$ and the $4 w_{0}$ to $2 w_{0}$ beam loadings are 1.06 and 1.08 respectively.

\subsection{ULTIMATE UNI-DIRECTIONAL PLASTIC HINGE ROTATION}

Very few structures have been tested in such a way that unidirectional plastic hinges form in the beams. Consequently it is difficult to determine limiting rotations or section ductilities. Two beams have been tested at Auckland, in one failure occurred at a plastic hinge rotation of 0.08 radians [3] and in the second, failure occurred at 0.065 radians [2]. In both these tests equal areas of top and bottom longitudinal reinforcement were used.

A number of analytical methods of predicting the inelastic rotation capacity in beam plastic hinge zones have been published in the literature $[12,13]$. With these, the curvature of the plastic hinge is assumed to be limited by the maximum strain that the concrete can sustain and the depth to the neutral axis. The application of these methods gives predicted ultimate plastic hinge rotations of the order of one third to one quarter of the experimentally observed values noted above. These methods do not appear to be appropriate for the case where the reinforcement in the compression zone can resist all the flexural compression force. In this situation spalling of the concrete may not lead to failure. This occurs when the compression reinforcement buckles or when the concrete in the web of the beam disintegrates to the extent the shear can no longer be resisted and the excessive shear deformation imposed on the compression reinforcement results in a buckling failure. 
To relate inelastic rotation demands to curvature ductilities it is necessary to find an effective plastic hinge length. A number of expressions have been given in the literature for this length. The application of the expression proposed by Corley, Mattock and Sawyer [12] and by Mander [14] to the experimental beams tested at Auckland give plastic hinge lengths which range from 0.42 to 0.60 times the total beam depth. Very similar values of plastic hinge length are obtained when the different expressions are applied to the beams in the analytical models used in the analyses. On this basis the effective plastic hinge length has been taken as half the total beam depth. Using this value the analytical results from the portal frame analyses imply section ductilities of up to 140 are required for the unidirectional plastic hinges. Standard elastic theory was used to calculate the curvature sustained at first yield of the reinforcement.

From the two tests made at Auckland on unidirectional plastic hinges, it is suggested a value of 0.06 radians might be an appropriate limiting value for beams with equal top and bottom reinforcement, with stirrups which comply with code requirements for ductile seismic resistant beams and where the shear stress levels do not exceed $0.28 \mathrm{Vf}^{\prime}{ }_{c}$. This rotation corresponds to a section ductility of approximately 50 with 300 grade reinforcement and 35 with 430 grade reinforcement. With higher shear stress levels or with unequal areas of top and bottom reinforcement the available section ductility would be less. Allowing for the $S_{p}$ value of 0.67 the 0.06 radian limit should be reduced to $0.06 / 1.2$ ( 0.05 radians) as outlined in section 5.3.

By interpolating between the results given in Tables 4 and 5 the limiting design ductility and inter-storey deflections corresponding to the rotation limit of 0.05 radians can be assessed. The results of these calculations are summarised in Table 6 for the three earthquake records for both the mean values and for the level at which 90 percent of the values will be less than the limit of 0.05 radians. It should be noted that the 0.05 radian limit is a tentative one as the experimental base is meagre. The indications are that this limit would need to be reduced for beams where the reinforcement in the compression zone was appreciably less than that in the tension zone.

The Loadings Standard [7] limits inter-storey deflections to 0.025 times the inter-storey height. Where elastic methods of analysis are used, such as the equivalent static or modal methods, lower limits such as 0.015 to 0.020 times the interstorey deflection are specified as these approaches have been found to under estimate the inter-storey deflections found from inelastic time history analyses. From the Table 6 data it is clear that where unidirectional plastic hinges are expected to form the currently accepted upper limits of structural ductility factor and inter-storey deflection need to be reduced to prevent strength degradation in a major (design level) earthquake. Alternatively, for new construction the potential formation of unidirectional plastic hinges can be suppressed by placing additional positive moment reinforcement in the beams as illustrated in Fig. 2.
Table 6: Inter-storey drift and ductility at limiting rotation of 0.5 radians (corresponding to section ductility of approximately 50 with 300 grade reinforcement).

\begin{tabular}{|c|c|c|c|c|}
\hline \multirow{2}{*}{$\begin{array}{c}\text { Seed } \\
\text { Earthquake }\end{array}$} & \multicolumn{2}{|c|}{ Mean values } & \multicolumn{2}{c|}{$\begin{array}{c}9 \% \text { less than } \\
\text { limit }\end{array}$} \\
\cline { 2 - 5 } & $\mu$ & Drift & $\mu$ & Drift \\
\hline & & & & \\
El-Centro & 4.5 & 0.025 & 3.6 & 0.025 \\
\hline Matahina & 4.7 & 0.025 & 4.0 & 0.025 \\
\hline Hachinoe & 3.6 & 0.025 & 2.9 & 0.025 \\
\hline & & & & \\
\hline El-Centro & 6 & 0.018 & 6 & 0.013 \\
\hline Matahina & 6 & 0.020 & 6 & 0.016 \\
\hline Hachinoe & 6 & 0.012 & 6 & 0.010 \\
\hline
\end{tabular}

\subsection{CONCLUSIONS}

1. Two forms of plastic hinge can form in the beams of ductile frames in a major earthquake. Reversing plastic hinges form where the gravity load levels acting on the beam are low, and unidirectional plastic hinges develop where this loading exceeds a critical value. With the reversing plastic hinge the maximum plastic hinge rotation is closely connected with the inter-storey drift. However, with the unidirectional plastic hinge this is not the case and the plastic hinge rotation continues to increase with the passage of the earthquake with the maximum value always being sustained at the end of the earthquake.

2. For the three earthquake records used in this investigation the rotation imposed on unidirectional plastic hinges was typically 2 to $4 \frac{1}{2}$ times the corresponding value acting on reversing plastic hinges.

3. The behaviour of reversing plastic hinges has been extensively researched and they can be designed with confidence. The same is not true of unidirectional plastic hinges both from the aspect of their behaviour under load and the inelastic rotations that they are required to sustain in design level earthquakes.

4. A simple two pin portal frame model with rigid columns was developed to enable the inelastic rotation demands of unidirectional plastic hinges to be assessed. The results obtained from this model were compared with values found using a six storey frame. As similar values were obtained from both models it was concluded that the simple portal model could be used to investigate the influence of a range of factors on the plastic hinge rotation. These included the load level acting on the beam, different inter-storey drift ratios and of ductility levels.

5. Some of the reasons advanced for using a $S_{p}$ factor of 0.67 in the Loadings Standard are not relevant to structures which form unidirectional plastic hinges. It is tentatively suggested that rotation demands found 
using a $\mathrm{S}_{\mathrm{p}}$ value of 0.67 should be increased by a factor of 1.2 to allow for this anomaly.

6. The design inter-storey drift ratio was found to have a significant influence on the inelastic rotation demand imposed on unidirectional plastic hinges. Changing this ratio from 0.025 to 0.020 and from 0.025 to 0.015 was found reduce the rotation demands to 81 and 65 percent of their previous values respectively.

7. The design ductility was found to have a major influence on the rotation demands. Reducing the ductility from 6 to 4 and from 6 to 2 was on average found to reduce the rotation demands to 66 and 28 percent of their initial values respectively.

8. Two tests at the University of Auckland, on beams which formed unidirectional plastic hinges, indicated that with shear stress levels of $0.28 \mathrm{Vf}^{\prime}{ }_{\mathrm{c}}$ or less and with equal top and bottom reinforcement a plastic hinge rotation of 0.065 radians could be sustained. This corresponded to a section ductility of approximately 55 with 300 grade reinforcement. Allowing for the $S_{p}$ factor of 0.67 , as discussed in point 4 above, and a level of uncertainty associated with the inadequate experimental base, it is suggested that the maximum design rotation should not be taken as more than 0.05 radians. This corresponds to a section ductility of approximately 40 with 300 grade reinforcement. In beams with different longitudinal top and bottom reinforcement areas this limit should be reduced.

9. To prevent the possibility of serious strength degradation in structures which may form unidirectional plastic hinges in major earthquakes the current allowable inter-storey drift and or ductility levels permitted in the Loadings and Concrete Standards $[6,7]$ need to be reduced.

\section{REFERENCES}

1. Fenwick, R. C. and Davidson, B. J. (1987), "Moment redistribution in seismic resistant concrete frames", Proceeding Pacific conference on Earthquake Engineering, Wairakei, New Zealand, Vol.1. pp. 95106

2. Davidson, B. J. and Fenwick, R. C. (1993), "Seismic response of ductile reinforced concrete frames with unidirectional plastic hinges", University of Auckland School of Engineering Report, No. 527, January, pp. 59

3. Megget, L.M. and Fenwick, R.C. (1989), "Seismic behaviour of a reinforced concrete portal frame sustaining gravity loads", Bulletin of NZ National Society for Earthquake Engineering, Vol. 22, No. 1, March, pp. 39-49.
4. Abrams, D. P. (1991), "Laboratory definitions of behaviour for structural components and building systems", SP 127, American Concrete Institute, pp. 91152

5. Dely, R. (1998), "Ductility demands for reversing and unidirectional plastic hinges in ductile concrete frames", Master of Engineering Studies Report, Department of Civil and Resource Engineering, University of Auckland, March, pp. 57.

6. Davidson, B. J. and Fenwick, R. C. (1997), "Ductility demands for reversing and unidirectional plastic hinges in ductile concrete frame structures", Proceedings NZNSEE Technical Conference, Wairakei, March, pp. 190-197.

7. Standards New Zealand (1992), "Code of practice for general structural design and design loadings for buildings, NZS4203-1992", Wellington N.Z.

8. Fenwick, R.C. (1991), "The behaviour of plastic hinge zones in seismic resistant concrete structures". SECED Conference Proceedings - Earthquake, Blast and Impact, Published Elsevier Applied Science, London, September, pp. 221-230.

9. Anaganostopoulas, S. A. and Roesset, J. M. (1974), "Ductility requirements for some non-linear systems subjected to earthquakes", Proceedings 5th. WCEE, Rome, Vol. 2, pp. 1748-1751.

10. Fenwick, R. C., Davidson, B. J. and Megget, L. M (1987), "Inelastic response of concrete structures", Technical report TR7, NZ Concrete Society, pp.95104.

11. Standards New Zealand, (1995) "Concrete Structures Standard, design of concrete structures, NZS31011995", Wellington, NZ.

12. Park, R. and Paulay, T. (1975), "Design of Concrete Structures", Wiley Interscience, pp. 769

13. Kemp, A. R. (1998), "The achievement of ductility in reinforced concrete beams", Magazine of Concrete Research, Vol. 50, No. 2, June, pp. 123-132.

14. Mander, J. B., Priestley, M. J. N. and Park, R. (1988), "Theoretical stress-strain model for confined concrete", ASCE Journal of Structural Engineering, Vol. 114, No.8, pp. 1804-1826. 